Revista Destaques Acadêmicos, Lajeado, v. 9, n. 4, 2017. ISSN 2176-3070 DOI: http://dx.doi.org/10.22410/issn.2176-3070.v9i4a2017.1396 www.univates.br/revistas

\title{
UM ORGANIZADOR PRÉVIO PARA A APRENDIZAGEM DE GEOMETRIA PLANA
}

\author{
Cassiano Scott Puhl ${ }^{1}$, Cristiana Monique Feltes ${ }^{2}$
}

Resumo: Este artigo apresenta uma unidade didática que se desenvolveu em forma de um organizador prévio, para a compreensão dos conceitos gerais sobre Geometria Plana, este que é um subsunçor para a aprendizagem da Geometria Espacial. Esse organizador prévio tem o objetivo de construir os subsunçores necessários, para o desenvolvimento de uma aprendizagem significativa por meio de manipulações e interações com colegas e com o professor, para a dedução das fórmulas de área de figuras planas. A unidade didática foi aplicada em uma turma de terceiro ano do Ensino Médio, da rede pública do Rio Grande do Sul, em que se observou a falta de subsunçores dos estudantes sobre Geometria Plana, sem este conhecimento, possivelmente, os estudantes podem apresentar dificuldades na compreensão dos conceitos da Geometria Espacial, ou de desenvolver uma aprendizagem mecânica. Desse modo, planejou-se um organizador prévio para que os estudantes sejam ativos no processo da construção de esquemas mentais sobre os conceitos gerais sobre Geometria Plana. A teoria de David Ausubel, de aprendizagem significativa, fundamentou o planejamento da unidade didática, que propõe também considerar o estudante como sujeito ativo nas atividades. Os dados coletados mostram indícios de que o organizador prévio foi eficaz, que os estudantes compreenderam os conceitos gerais sobre Geometria Plana e utilizaram esses conhecimentos em situações mais complexas do que proposto inicialmente.

Palavras-chave: Área de figuras planas. Ensino Médio. Aprendizagem Significativa.

\section{INTRODUÇÃO}

A Geometria é um conceito matemático estudado durante a Educação Básica, iniciando no primeiro ano do Ensino Fundamental, que busca desenvolver o pensamento geométrico dos estudantes, proporcionando as capacidades de investigação de propriedades, elaboração de conjecturas e argumentos geométricos convincentes (BRASIL, 2017). Mas infelizmente

1 Aluno de doutorado do Programa de Pós-graduação em Educação de Ciências e Matemática da PUCRS. E-mail: c.s.puhl@hotmail.com.

2 Licenciada em Matemática pela UNISINOS. E-mail: cristianafeltes@hotmail.com. 
essas capacidades não estão sendo desenvolvidas pelos estudantes, pois a Geometria tem tido pouco destaque nas aulas de Matemática que, muitas vezes os professores acabam privilegiado a Álgebra (BRASIL, 1998). Nessa pesquisa deter-se-á na abordagem da Geometria Plana (GP) e da Geometria Espacial (GE), sendo que a GP é um conhecimento base, um subsunçor necessário para a aprendizagem significativa da GE, conteúdo geralmente estudado no Ensino Médio (BRASIL, 2002; BRASIL, 2017). A GP por se tratar de um conhecimento que desperta o interesse dos jovens e de fácil visualização da sua aplicação (BRASIL, 1998), pode apresentar uma predisposição dos estudantes para compreender os conceitos e os algoritmos para determinar a área de figuras planas.

Em um contexto de Ensino Médio, espera-se que os estudantes tenham o conhecimento básico sobre GP, mas a experiência profissional mostra que os estudantes não compreendem e não sabem calcular a área dessas figuras. Complementando esse cenário, a Base Nacional Comum Curricular (BNCC) afirma que:

“[...] a Geometria não pode ficar reduzida a mera aplicação de fórmulas de cálculo de área e de volume nem a aplicações numéricas imediatas de teoremas sobre relações de proporcionalidade em situações relativas a feixes de retas paralelas cortadas por retas secantes ou do teorema de Pitágoras" (BRASIL, 2017, p. 270).

Assim, se faz necessário utilizar uma estratégia que o estudante aprenda os conceitos da GP, para posteriormente aplicá-los no estudo da GE, e compreenda as fórmulas para o cálculo de área das seguintes figuras planas: retângulo, triângulo, trapézio, losango e círculo. Porém, no mundo real dificilmente se encontra figuras planas perfeitas, assim decidiu-se proporcionar uma atividade para que os estudantes determinassem a área de outras figuras, em que utilizariam sua criatividade para decompor a figura em outras formas geométricas para calcular a área total.

Vivenciado essa realidade, em que os estudantes não possuem subsunçores, o conhecimento das fórmulas da área da maioria das formas geométricas, optou-se por planejar uma unidade didática, um organizador prévio, contemplando os conceitos de GP para, posteriormente, utilizar esse conhecimento como "ancora" para a aprendizagem da GE. Essa unidade didática foi planejada e aplicada a 30 estudantes de um terceiro ano do Ensino Médio, da rede estadual de ensino do Rio Grande do Sul, durante o primeiro semestre de 2017. Para fundamentar a construção dessa unidade didática utilizou-se a teoria da Aprendizagem Significativa.

Neste trabalho de pesquisa, instaura-se o seguinte problema: A unidade didática planejada e aplicada propiciou a aprendizagem das formas de cálculo da área de formas geométricas? 
A pesquisa desenvolveu-se nas seguintes etapas:

- Diagnóstico dos conhecimentos prévios, por meio de um questionário inicial, sobre a nomenclatura e o cálculo de área de figuras planas (quadrado, retângulo, triângulo qualquer e equilátero, losango, paralelogramo, trapézio, pentágono, hexágono, octógono e círculo).

- Explicação do cálculo da área de um retângulo, por meio do papel quadriculado.

- Organização da turma em grupos para a pesquisa da forma de resolução da área de outras figuras planas.

- Compartilhamento dos resultados das pesquisas do grupo de estudantes.

- Resolução de exercícios, situações-problemas, proposta pelos grupos da turma.

- Medição e construção da plana baixa do prédio da escola, calculando a sua área total e representando-a numa maquete.

- Reaplicação do questionário inicial para analisar se a unidade didática (re)construiu novas aprendizagens.

- Aplicação de questionário, com o objetivo de analisar as percepções dos estudantes.

Seguindo essas etapas, com os dados coletados, pretende-se mostrar indícios de que a unidade didática se efetivou como um organizador prévio, proporcionando subsunçores para a aprendizagem de conceitos da GE.

\section{FUNDAMENTAÇÃO TEÓRICA}

Arbach (2002) relata duas situações preocupantes sobre o ensino de geometria plana: sendo um tema pouco explorado em pesquisas científicas e seu ensino geralmente reduzido a cálculos algébricos. Os Parâmetros Curriculares Nacionais do Ensino Médio ( $\mathrm{PCN}+$ ) já afirmavam que o ensino da geometria não pode se restringir a memorização e a aplicação de fórmulas para o cálculo de área de figuras planas ou do volume de alguns sólidos (BRASIL, 2002). O mesmo relato é apontado na BNCC (BRASIL, 2017), ou seja, é cenário que em mais de uma década não se alterou e é preocupante. Nesta etapa da Educação Básica, no Ensino Médio, o estudante deve analisar, compreender e deduzir as fórmulas para esses tipos de operações (BRASIL, 2002).

Para se atingir esse objetivo planejou-se uma unidade didática fundamentada nos PCN+ (BRASIL, 2002) e na teoria de aprendizagem significativa (AUSUBEL, 2003). Nessa unidade didática, o estudante não será um mero receptor de conhecimento, mas sim, sujeito ativo no processo de aprendizagem. O estudante terá que criar hipóteses, manipular objetos e interagir com colegas e com o professor até compreender a forma de calcular a 
área de figuras planas. Desta forma, o discente atingirá um nível de abstração superior a uma mera reprodução de uma fórmula matemática.

Sobre a GP, especificamente do conceito de área, os PCN+ elencam alguns objetivos básicos: analisar e interpretar diferentes representações de figuras planas, como desenhos, mapas e plantas; usar formas geométricas planas para representar ou visualizar partes do mundo real; e utilizar o uso de escalas em representações planas (BRASIL, 2002).

Visando atingir esses objetivos propostos pelos $\mathrm{PCN}+$, a teoria de aprendizagem significativa fundamentou a construção da unidade didática. Segundo Ausubel, Novak e Hanesian, "[...] a essência do processo de aprendizagem significativa é que as ideias expressas simbolicamente são relacionadas às informações previamente adquiridas através de uma relação não arbitrária e substantiva (não literal)" (1980, p. 34).

Em relação à substantividade, pode-se dizer que é a característica mais desejada pelos estudantes, uma vez que se refere ao desenvolvimento de uma aprendizagem com sentido, que indica que há compreensão do significado daquilo que aprende, indicando aplicabilidade e utilidade. Em outras palavras, a substantividade representa o significado que o estudante constrói de um conhecimento novo, por meio dos subsunçores disponíveis em seus esquemas mentais.

$\mathrm{O}$ conceito da não arbitrariedade refere-se à necessidade de que o conceito novo estabelece alguma ligação com um subsunçor do estudante. Esta ligação entre o conhecimento novo e o subsunçor é o ponto mais importante no processo de aprendizagem (MOREIRA, 2011a). Se ela for significativa, ocorrerá uma relação de conceitos entre o subsunçor e o conhecimento novo. Quando o estudante compreender o conhecimento novo, ele pode ser considerado um subsunçor para a aprendizagem de novos conceitos mais específicos e complexos. Desse modo, uma aprendizagem significativa não tem fim, pois os conhecimentos, os subsunçores, sempre estão sendo ampliados e se tornando mais complexos (MIRAS, 1999).

Em algumas situações, os estudantes não apresentam os subsunçores para a aprendizagem de novos conceitos, desta forma, se faz necessária a utilização de um organizador prévio para construção deste subsunçor. Caso contrário, têm-se fortes indícios de que se desenvolverá uma aprendizagem mecânica, em que o estudante reproduzirá fórmulas ou conceitos. Segundo Moreira: "Organizadores prévios são materiais introdutórios apresentados antes do material de aprendizagem em si" (2011b, p. 11). Geralmente, são textos, atividades ou outros recursos didáticos que abordam alguns conceitos gerais, os subsunçores, que serão utilizados na construção de novos conceitos.

Completando este pensamento, "[...] os organizadores prévios são úteis para facilitar a aprendizagem na medida em que funcionam como 'pontes 
cognitivas'". (MOREIRA; MASINI, 2006, p. 21). Quer dizer, o organizador prévio serve como estrutura básica para se alcançar um novo conhecimento.

A substantividade e a não arbitrariedade são características fundamentais para o desenvolvimento de uma aprendizagem significativa. Além disso, Ausubel (2003) também destaca a importância da predisposição do estudante em aprender.

Assim, a seguinte questão merece reflexão: “É possível orientar alguém que não quer aprender?" Isto é impossível, porque para Ausubel (2003), a aprendizagem significativa somente se efetivará se o estudante tiver vontade de aprender; assim, além de mediador o professor tem a função de desafiador, ou seja, deve despertar a curiosidade para a aprendizagem de novos conhecimentos. Uma forma de motivar os estudantes é através da abordagem de situações-problemas sobre o conteúdo estudado, podendo dar sentido a este assunto. Outra forma, possivelmente, mais eficaz é utilizar estratégias com que o estudante se sinta sujeito no processo de sua aprendizagem, atendendo as características da não arbitrariedade e da substantividade.

Partindo desses fundamentos teóricos, planejou-se um organizador prévio, buscando em suas estratégias e atividades o desenvolvimento de um ambiente reflexivo e investigativo, para a compreensão e dedução das fórmulas de área das figuras planas, tendo os estudantes como sujeitos ativos e o professor um mediador no processo de aprendizagem.

\section{UNIDADE DIDÁTICA}

A atividade foi planejada considerando a teoria de aprendizagem significativa. Segundo Ausubel (2003), os subsunçores são fundamentais para se desenvolver uma aprendizagem significativa, desta forma, a primeira atividade consistiu de um questionário para verificar os conhecimentos dos estudantes. O questionário era referente à GP, composto de exercícios sobre a nomenclatura de figuras planas, bem como o cálculo de suas respectivas áreas e de situações-problemas. Antes da aplicação desse questionário, os estudantes não haviam estudado sobre Geometria Plana (GP) ou Geometria Espacial (GE) no Ensino Médio, pois o assunto está presente no currículo do terceiro ano da escola de Ensino Médio. Assim havia-se a hipótese que os estudantes apresentariam dificuldades, pois, somente, tiveram uma introdução sobre GP no Ensino Fundamental.

Tendo a hipótese de que os estudantes não tinham os conhecimentos básicos sobre GP, construiu-se uma unidade didática, um organizador prévio, para o estudo dos conceitos bases de GP. Para essa construção, utilizou-se papel quadriculado, para que os estudantes compreendessem e definissem a forma de resolver a área do retângulo. Dando continuidade, solicitou-se a representação de um triângulo, no papel quadriculado, para que estabelecessem uma relação matemática para calcular área de um triângulo, por meio da medida da base 
e da altura. O professor foi o mediador no processo da aprendizagem, onde questionou e incentivou as discussões, a troca de conhecimento entre os colegas. Assim, compreendendo as fórmulas de área do retângulo e do triângulo, os estudantes puderam avançar nos estudos.

Visando o desenvolvimento de um estudante ativo, organizaram-se grupos de estudos para o estudo do cálculo da área de uma figura plana, como: trapézio, paralelogramo e losango. Utilizando a criatividade e os conhecimentos sobre retângulo e triângulo, os estudantes elaboram formas para determinar as áreas dessas figuras, decompondo-as. Aumentando a dificuldade das abstrações para o cálculo de área, repetiu-se a mesma estratégia com outras figuras: pentágonos, hexágonos e círculos. Os grupos estudaram na web as figuras escolhidas, procurando compreender a forma de calcular a área da figura, já que por meio somente da decomposição não conseguiram determinar as respectivas medidas de área. Após esse estudo, os grupos compartilharam seus estudos, propondo três exercícios, em níveis de dificuldade diferentes, para a turma resolver, sendo responsabilidade do grupo a correção dos exercícios. Os grupos trabalharam em dois momentos: inicialmente orientado os colegas na resolução dos exercícios individualmente, tirando dúvidas pontuais; e resolvendo as atividades no quadro para a turma.

Concluindo a unidade didática, disponibilizou-se uma planta de imóvel para os estudantes analisarem, composta por quadriláteros. Nesta atividade, além de calcular a área total, determinou-se o custo aproximado dos materiais e da mão de obra. Para complementar essa atividade, os estudantes, em grupos, mediram com trena as dimensões da escola, e com o auxílio de um teodolito caseiro e conceitos de trigonometria, determinaram a altura do prédio da escola ${ }^{3}$. O teodolito caseiro (FIGURA 1) foi construído com: um copo descartável com tampa, um canudinho, um pedaço de arame de 15 centímetros, uma cópia de um transferidor de 360 graus, fita e cianoacrilato (Super Bonder). Com essas informações, cada grupo, construiu a planta baixa, uma maquete do prédio da escola e estimaram a área total da escola.

3 A altura do prédio era uma medida necessária para a realização da maquete em escala, bem como para determinar a quantidade aproximada de material gasto na sua construção. 
Figura 1 - Teodolito caseiro construído pelos estudantes

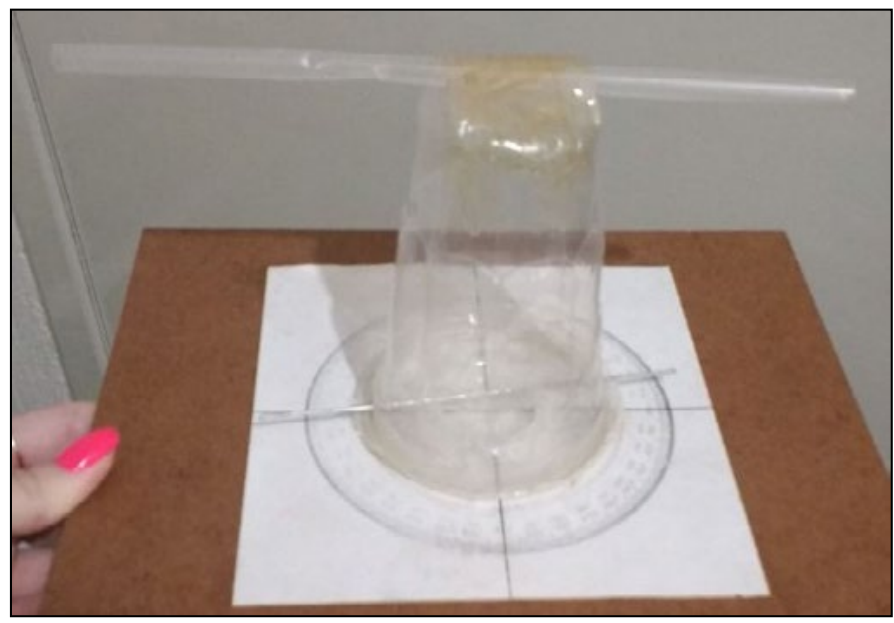

Fonte: Elaborada pelos autores

Após a aplicação dessa unidade didática, aplicaram-se dois questionários: um para analisar as aprendizagens desenvolvidas durante a unidade didática; e outro, avaliando o planejamento e desenvolvimento da unidade didática. Desse modo, pode-se comparar os subsunçores dos estudantes, antes e após o organizador prévio, apresentando indícios da eficácia da unidade didática.

\section{RESULTADOS DA UNIDADE DIDÁTICA}

Inicialmente, para verificar os subsunçores dos estudantes, aplicou-se um questionário composto por nove exercícios sobre GP. A primeira questão verificava se os estudantes saberiam fazer a ligação entre o nome e a imagem de determinada figura geométrica. Os estudantes identificaram corretamente $o$ quadrado, o retângulo, o paralelogramo e o círculo, porém, tiveram dificuldade em outras, como o trapézio, o losango, o pentágono, o hexágono e o octógono.

Dando continuidade, as próximas atividades tinham o objetivo de verificar se os estudantes saberiam calcular a área de seis figuras planas (quadrado, retângulo, trapézio, triângulo qualquer, paralelogramo e hexágono). O Gráfico 1 mostra o percentual de acertos em relação a cada figura geométrica abordada. 
Gráfico 1 - Percentual de acertos por questões das figuras geométricas estudadas.

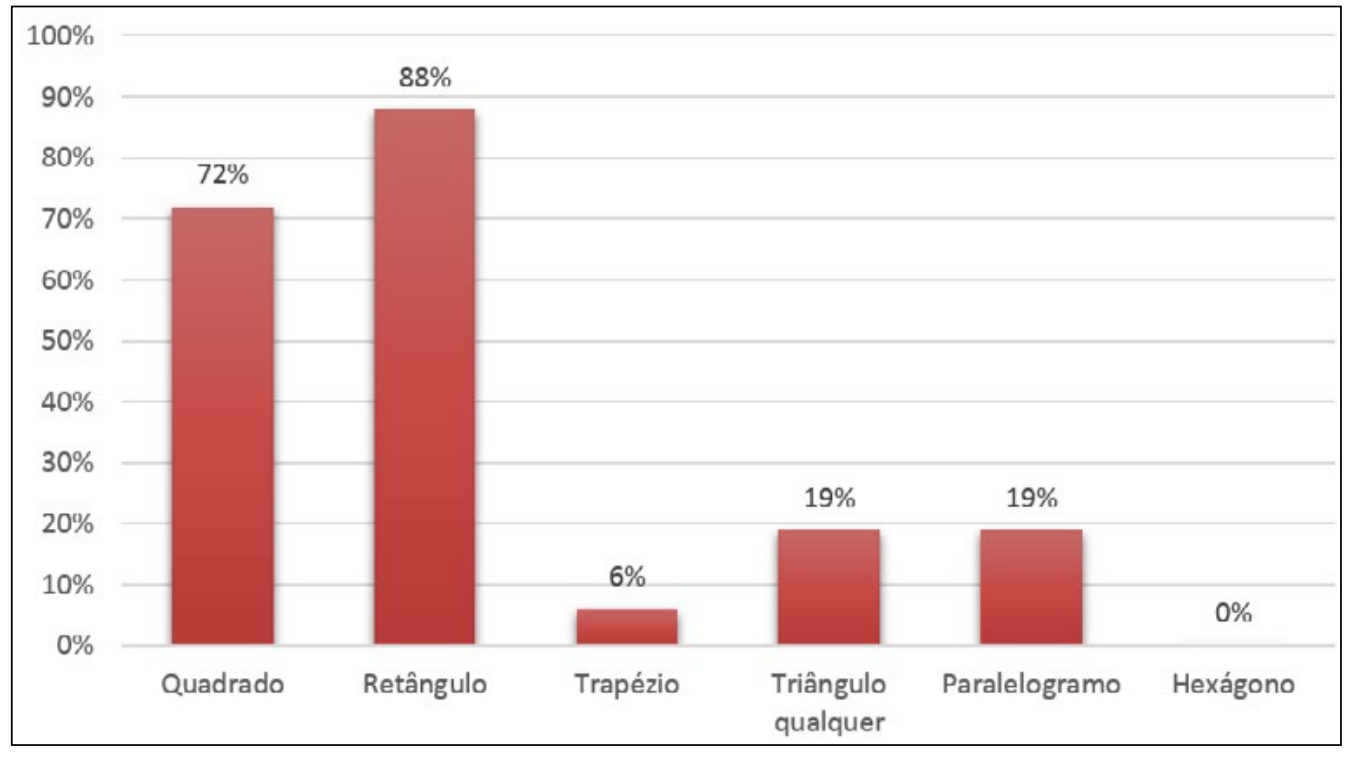

Fonte: Elaborada pelos autores com base no questionário inicial aplicado.

O gráfico refere-se ao percentual de estudantes que acertou a área de cada figura específica na questão 2 , sendo que da turma toda analisada, $72 \%$ acertaram a área do quadrado, 88\% acertaram a área do retângulo, 6\% acertaram a área do trapézio, $19 \%$ acertaram a área do triângulo qualquer, 19\% acertaram a área do paralelogramo e 0\% acertaram a área do hexágono. Esses dados mostram indícios de ser necessária a utilização de um organizador prévio para a reconstrução desses conceitos.

Aumentando o grau de complexidade, foram propostos sete problemas matemáticos, alguns com alternativas e outros somente com o enunciado, mas o resultado foi desanimador. Somente três problemas tiveram índices de acertos, $63 \%$ da turma acertou o problema que envolvia o cálculo do perímetro e área de um campo de futebol, $13 \%$ calcularam a área de uma coroa circular e $28 \%$ determinaram a área de polígono formado por um retângulo e por um triângulo. Um fato causou estranheza, pois havia uma questão que os estudantes deveriam determinar a área de moeda circular e ninguém acertou, esta apresentava somente o enunciado, porém 13\% acertaram o problema sobre a coroa circular, que era uma questão objetiva, isso mostra indícios que, provavelmente, os $13 \%$ não sabiam fazer a questão, porém assinalaram a alternativa correta.

Esses dados mostram indicativos que os estudantes não tinham os subsunçores necessários para a aprendizagem da GE. Desta forma, aplicou-se a unidade didática para que os estudantes compreendessem a forma de calcular a área do quadrado, do retângulo e do triângulo. Nesta etapa foi distribuído 
papel quadriculado e solicitado que os estudantes construíssem um quadrado ou retângulo qualquer e determinassem a área da figura. Provavelmente, no Ensino Fundamental já haviam estudado e trabalhado o conceito de área por meio dessa atividade, pois mostraram facilidades em determinar a área, seja contando os quadrados ou realizando a multiplicação da base pela altura. Em seguida, os estudantes foram desafiados a construir um triângulo e determinar a área. Nesta parte, contar quadradinhos ficou difícil. O professor atento a essa situação e mediu o processo da construção desse conhecimento, sugerindo a construção de um triângulo retângulo para que o estudante fizesse a comparação entre o triângulo com o retângulo. Um estudante falou: "É a metade, então fazemos base vezes altura e dividimos por dois!". Porém essa situação é especifica para um triângulo, assim para convencer os estudantes dessa fórmula matemática, realizou-se outros exemplos com triângulos de diferentes classificações, confirmando a hipótese estabelecida.

Propondo o cálculo da área de outras figuras planas, os estudantes separaram a figura em retângulos e triângulos para calcular a área total. A Figura 2 mostra como os estudantes procederam na realização dos cálculos da área de trapézio, losango, pentágono e hexágono. As medidas das figuras eram reais, assim os estudantes fizeram uso de régua para fazer as medições e determinar a área.

Figura 2 - Forma que os estudantes realizaram os cálculos de área

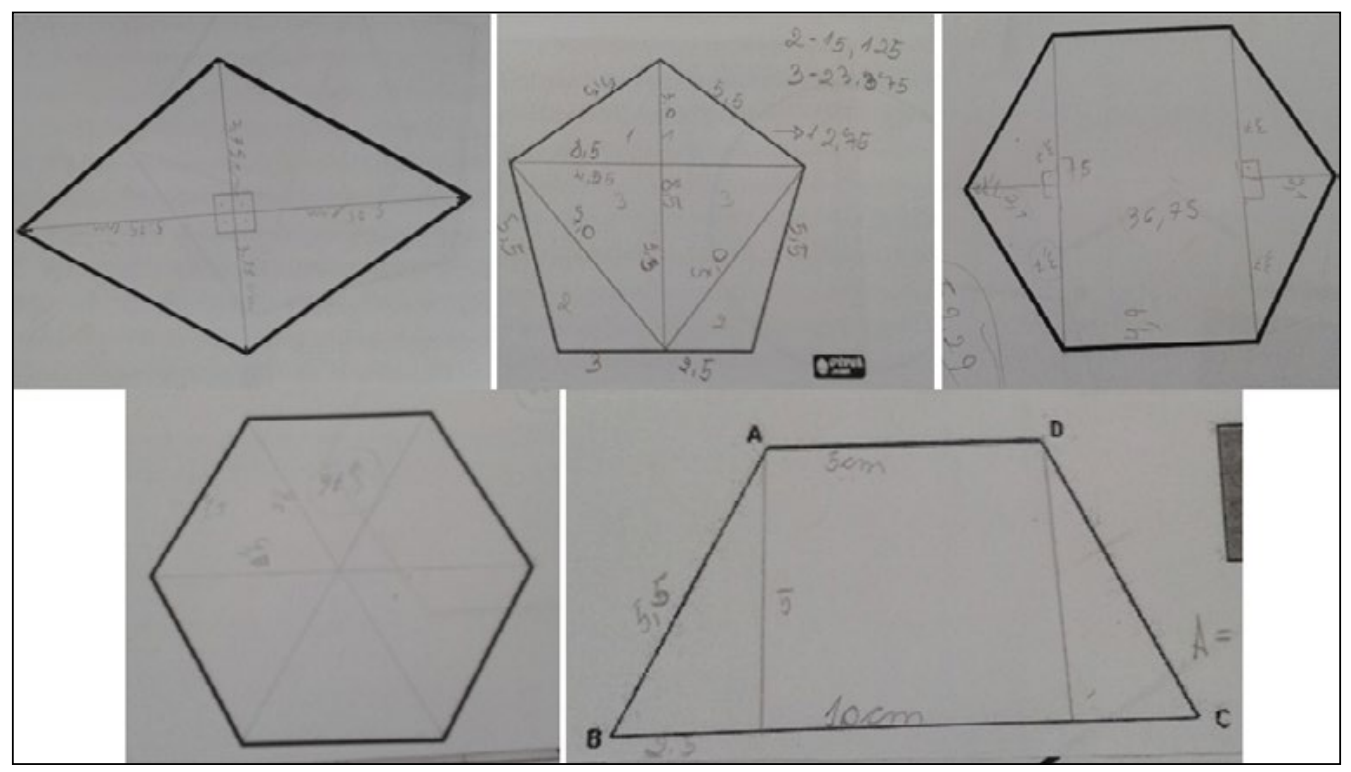

Fonte: Elaborada pelos autores. 
Ao final da tarefa, os estudantes apresentavam suas resoluções para a turma, e concluiu-se que há diferentes formas para calcular a área dessas figuras, não sendo necessário memorizar as fórmulas de cada figura.

Mas, a forma mais rápida é por meio da utilização das fórmulas. Desta maneira, os estudantes foram separados em grupos e cada um estudou a forma de calcular a área de determinada figura (trapézios, paralelogramos, losangos, pentágono, hexágono e círculo). Alguns grupos apenas apresentaram as fórmulas das áreas, outros realizaram demonstrações e atividades interessantes, as quais conheciam a resolução. Infelizmente nem todos os grupos mostraramse interessados e motivos nessa etapa da unidade didática, não estudaram e não realizaram a atividade proposta. Esses estudantes acabaram prejudicados cognitivamente na atividade seguinte, pois para Ausubel (2003) um fator primordial para a compreensão dos conceitos estudados, é a vontade de aprender, ou seja, a predisposição do estudante.

Oestudantecomosujeitoativo, acabou influenciandonodesenvolvimento das próximas atividades, pois os colegas que não estavam preparados, que não compreenderam a sua figura e nem o exercício proposto, acabaram atrapalhando a continuidade da unidade didática. A próxima atividade da unidade didática requeria que os estudantes tivessem compreendido as fórmulas de área para utilizá-las em uma aplicação real. Enquanto boa parte do grupo estava com os subsunçores prontos para serem ativados, a minoria, os que não tinham participado estavam sem esse conhecimento.

Contrapondo o grupo que não se motivou, destaca-se o grupo que realizou o estudo da área do círculo, pois trouxeram uma atividade em que consistia transformar um círculo num retângulo, preservando alguns elementos do círculo, para determinar a sua área (FIGURA 3). Os estudantes concluíram que jamais poderiam formar um retângulo, porém quanto menor fossem os pedaços mais próximo seria de um retângulo. Desse modo, o grupo explicou para a turma a fórmula da área do círculo.

Figura 3 - Atividade realizada por um grupo de estudantes

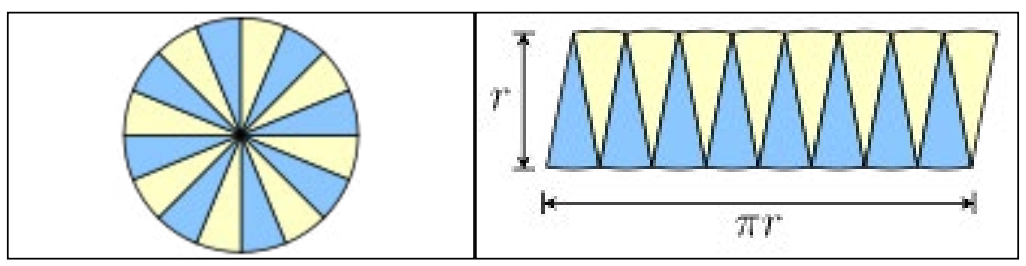

Fonte: Elaborada pelos autores.

Seguindo a unidade didática, os estudantes foram desafiados a medirem as dimensões da escola com uma trena para calcular a área total do prédio, posteriormente construir uma planta e uma maquete da escola. Os estudantes 
foram separados em grupos, em que cada grupo era responsável por medir e calcular a área de determinado local da escola (FIGURA 4). Um trabalho árduo, pois, exigiu a organização para realizar as medições, as representações e os cálculos.

Em busca de ajudar os estudantes desmotivados da atividade anterior, eles foram separados de modo que ficassem em grupos com estudantes que possuíam os subsunçores necessários. Desse modo, além de realizar medições os estudantes que estiveram ativos durante toda a unidade didática auxiliaram os colegas, trocando ideias e conhecimentos.

Figura 4 - Estudantes fazendo medições na escola

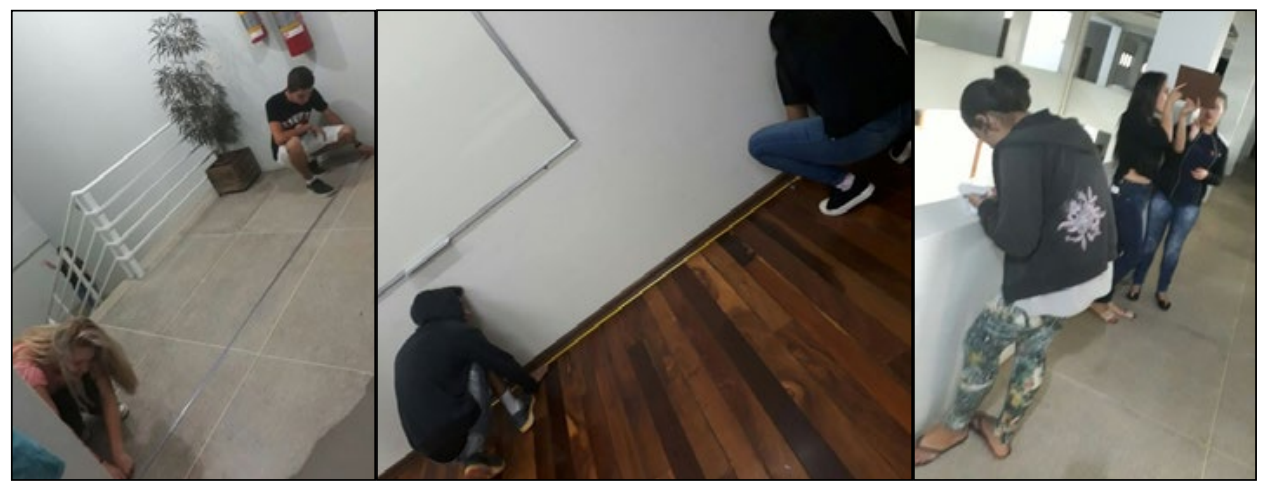

Fonte: Elaborada pelos autores.

Ao concluir a atividade das medições, em sala de aula, um estudante montou um rascunho da planta da escola no quadro (FIGURA 5), com o objetivo de juntar as diferentes dimensões encontradas pelos grupos. 
Figura 5 - Planta representada no quadro pelos estudantes

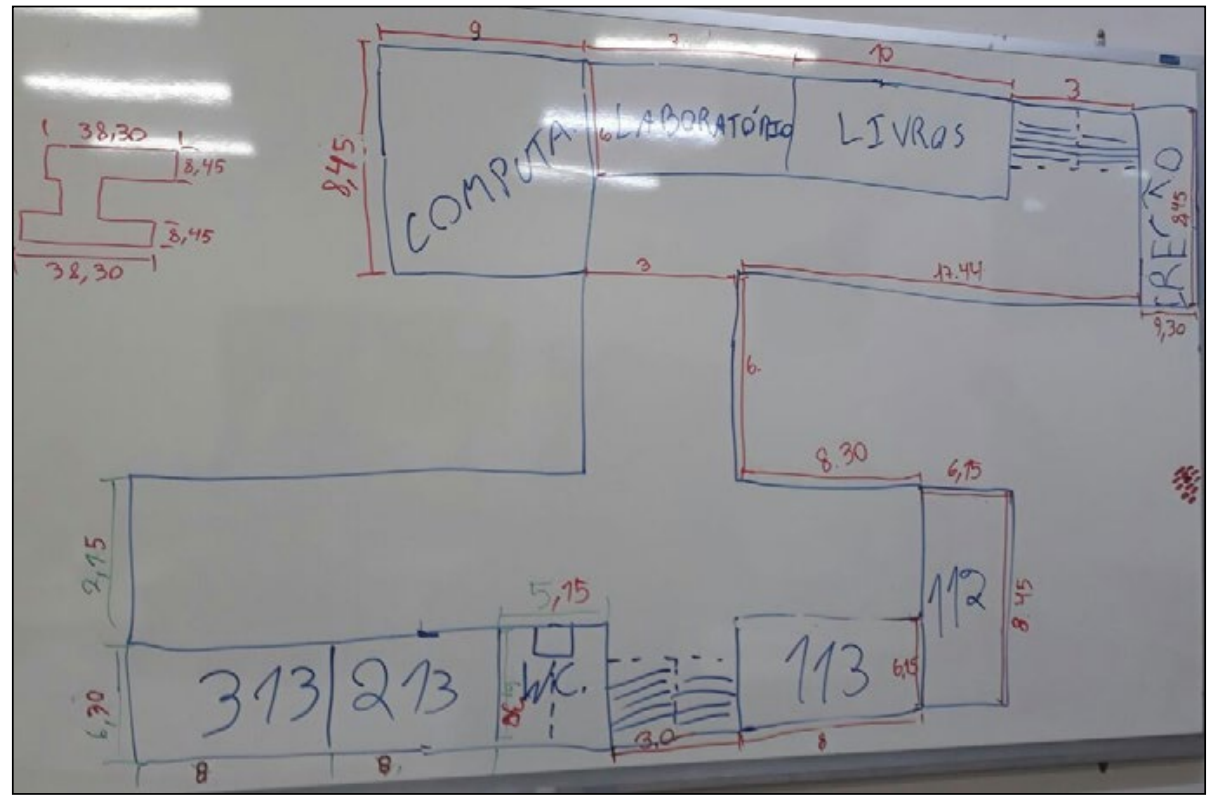

Fonte: Elaborada pelos autores.

Representada a planta da turma, esta foi comparada com a planta original da escola, e observou-se que algumas medidas tiveram diferença de centímetros, o que demonstra a predisposição dos estudantes e a precisão das medições e dos cálculos realizados. Desta forma, a planta da turma ficou muito próxima das medidas originais.

A etapa seguinte consistia na construção da maquete da escola (FIGURA 6). Inicialmente, planejou-se a construção de uma maquete para a turma, porém os estudantes não gostaram da ideia e relataram que preferiam construir uma por grupo, que facilitaria o trabalho deles, permitindo também o maior envolvimento deles na atividade.

A construção da maquete permitiu que os estudantes desenvolvessem outras capacidades, além dos conhecimentos matemáticos, sendo uma estratégia utilizada para retomar os conceitos de escala e proporção. Assim, os estudantes receberam a tarefa de realizar as medidas na escola, bem como desenhar a planta em determinada em escala em uma folha A3 para, posteriormente, realizar a construção da maquete, em determinada escala. 
Figura 6 - Maquete construída por um grupo de estudantes

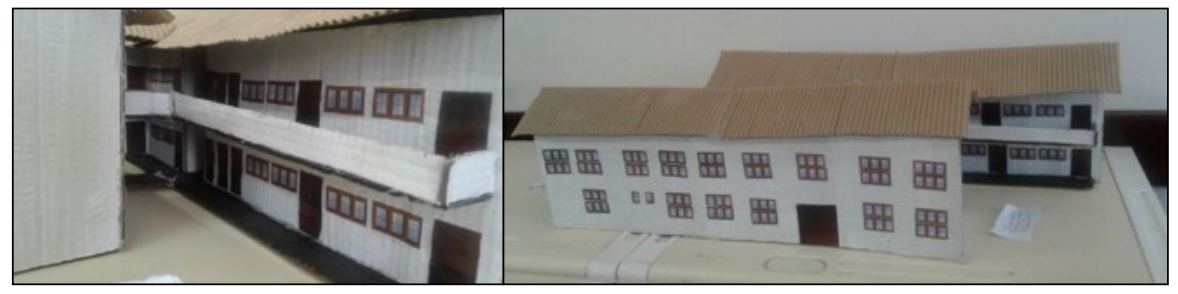

Fonte: Elaborada pelos autores.

Para concluir a unidade didática, decidiu-se reaplicar o questionário inicial e comparar os resultados com a análise inicial. A primeira atividade tinha o objetivo de relacionar a figura plana com a sua nomenclatura, sendo que $52 \%$ da turma relacionou de forma correta todas as opções, $37 \%$ relacionaram mais da metade das opções de forma correta, e $11 \%$ relacionaram menos da metade de forma correta.

A segunda questão, referente ao cálculo da área de algumas figuras planas (quadrado, retângulo, trapézio, triângulo qualquer, paralelogramo e hexágono), os resultados estão representados no Gráfico 2, fazendo uma comparação dos resultados inicialmente e depois da aplicação do organizador prévio.

O gráfico mostra o avanço que os estudantes tiveram, em relação a todas as figuras geométricas, os índices melhoraram. Porém, observa-se que a maioria da turma não soube resolver a área de um trapézio e de um hexágono. Em sala de aula, observou-se que os estudantes tinham a preocupação de memorizar as fórmulas estudadas e apresentadas pelos colegas, um fator que auxiliou para que não resolvessem as questões com trapézio e hexágono. Em busca de auxiliar os estudantes, relatou-se que poderiam utilizar a decomposição para determinar a área, sendo que a maioria dos estudantes que souberam fazer utilizaram essa estratégia de resolução. Ressalta-se que os dados apresentados no Gráfico 2 são referentes aos exercícios para determinar a área das figuras, sem serem aplicados em situações-problemas. 
Gráfico 2 - Percentual de acertos por questão

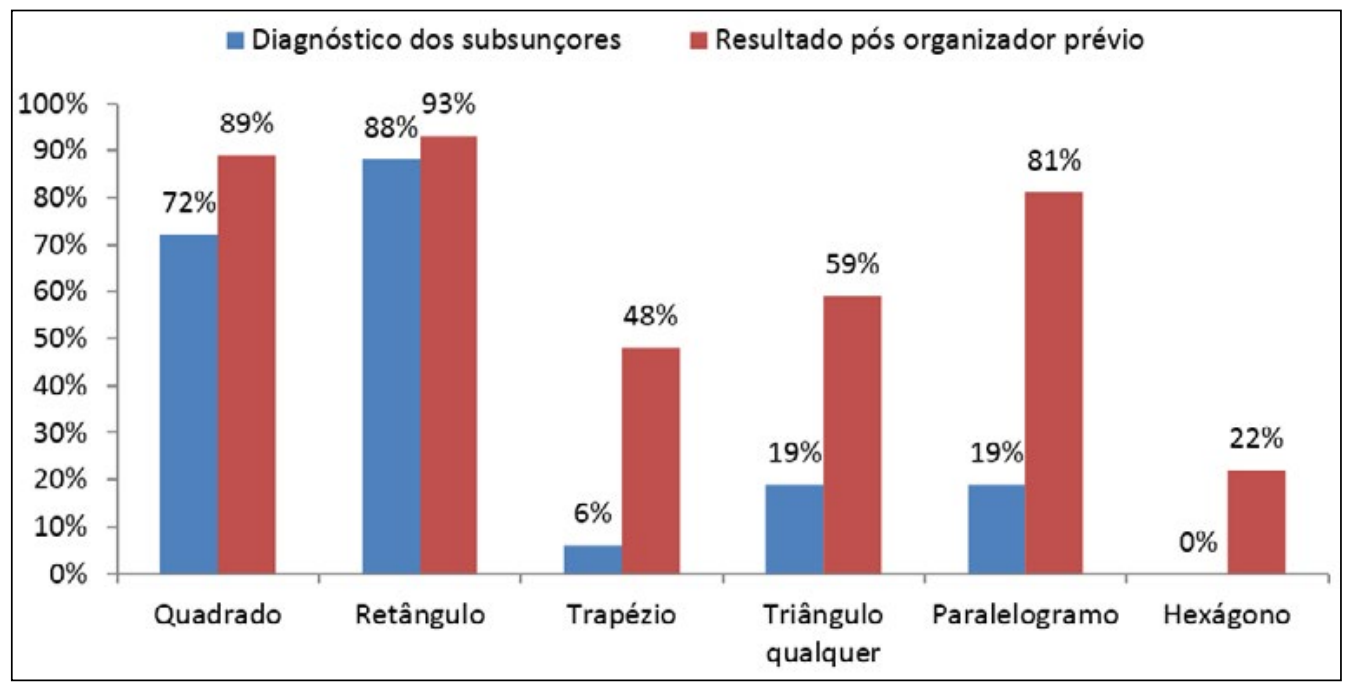

Fonte: Elaborada pelos autores com base nos questionários aplicados.

Em relação as situações-problemas, os resultados foram acima do esperado. A contextualização do exercício pode ter sido uma característica para que os estudantes estivessem predispostos para resolver os exercícios, construindo significado dos novos conhecimentos estudados. A maioria dos estudantes acertaram todos os sete problemas matemáticos, sendo que os menores índices de acertos foram $74 \%$ em problemas que envolviam o cálculo da área da moeda circular e do perímetro de um quadrado, cuja informação dada era a área do mesmo; $78 \%$ acertaram a área da coroa circular e do polígono formado pelo retângulo e pelo triângulo; $85 \%$ acertaram a área de um losango; $\mathrm{e}$ todos acertaram de determinar a área de um trapézio e o problema do campo de futebol. Assim, os estudantes apresentam indícios de grau de significado maior sobre as situações-problemas do que os exercícios anteriores que solicitava a determinação da área de determinada figura.

Por fim, aplicou-se um questionário para analisar as percepções dos estudantes, quanto ao que aprenderam, como aprenderam e como consideraram sua aprendizagem. Dos 30 questionários analisados, 48\% responderam que compreenderam de forma plena os conteúdos, justificando que tiveram algumas dificuldades no desenvolvimento de algumas atividades, outros disseram que preferem aulas expositivas $; 48 \%$ responderam que compreenderam de forma satisfatória e que as atividades mostraram a aplicabilidade da geometria no dia-

4 Em relação a turma, 13\% argumentaram que preferem a explicação do professor, pois possuem dificuldades na compreensão dos conceitos de Matemática, como pode ser observado na Figura 7. 
a-dia, sem memorizar fórmulas; e 4\% responderam que não compreenderam o conteúdo, justificando que não gostam de matemática, não "vê" sentido no estudo da disciplina e também não tem interesse, mostrando que não possui predisposição em aprender.

Figura 7 - Exemplo de justificas apresentadas pelos estudantes

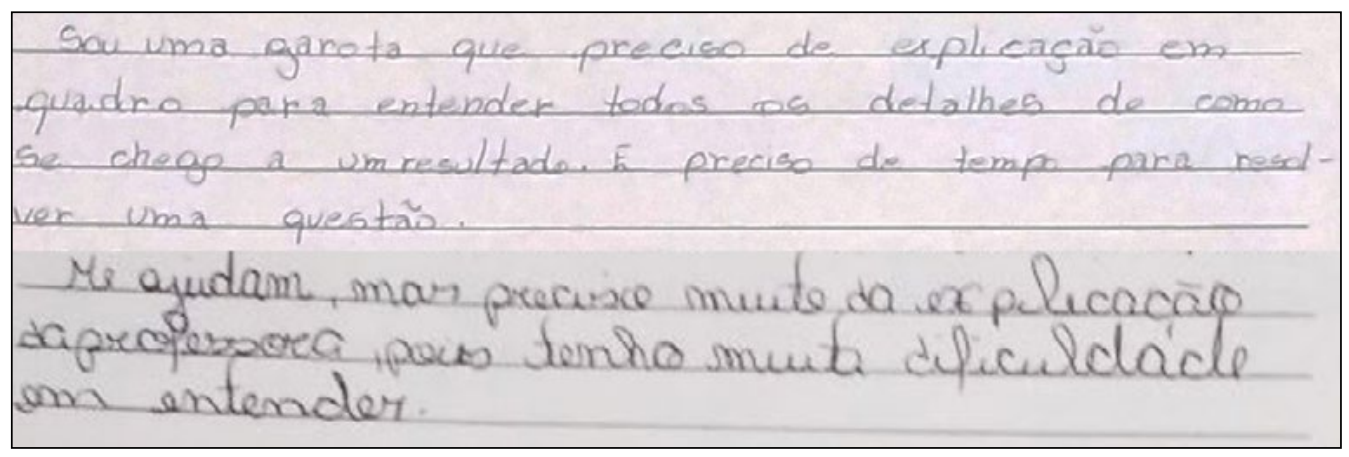

Fonte: Elaborada pelos autores.

Esses dados revelam que os estudantes não estão acostumados a tomar o posto de sujeitos ativos no processo de aprendizagem, sendo que alguns preferem receber as informações sendo passivos na sala de aula. Porém, como o objetivo de BNCC não é a memorização de fórmulas, um pouco menos da metade dos estudantes mostrou-se satisfeito com a unidade didática e com papel ativo no decorrer das atividades, um indício da predisposição desses estudantes em compreender os conceitos estudados.

A próxima questão tinha por objetivo verificar se o estudo da GP foi importante para relembrar alguns conceitos, $59 \%$ responderam que sim, pois não recordavam do conteúdo; $33 \%$ responderam que sim, pois recordavam apenas de algumas figuras planas; $4 \%$ responderam que não, pois não está interessado em aprender; e 4\% não responderam a questão. Assim, o organizador prévio desempenhou seu objetivo de proporcionar os subsunçores necessários para o estudo e a compreensão dos conceitos de GE, que foram estudados posteriormente.

Em relação à participação do estudante nas atividades propostas, $70 \%$ disseram ter participado plenamente, compreendo os conteúdos estudados; $4 \%$ responderam que participaram parcialmente, e que o conteúdo foi compreendido; $14 \%$ disseram que participaram parcialmente, e que não compreenderam o conteúdo; $4 \%$ responderam que participaram parcialmente, e que o conteúdo não teve significado; e $4 \%$ disseram que não participaram, pois não os interessou. Nesse aspecto, a unidade didática apresenta indícios de ser um recurso potencialmente significativo, pois a maioria dos estudantes mostraram predisposição em realizar as atividades e na compreensão dos 
conceitos. Desse modo, os estudantes, possivelmente, desenvolveram em algum grau a capacidade de investigação de propriedades, elaboração de conjecturas e argumentos geométricos convincentes, conforme é proposto na BNCC (BRASIL, 2017).

\section{CONSIDERAÇÕES FINAIS}

Ensinar, desenvolver planejamentos, estratégias e ambientes propícios para aprendizagens é um desafio para os professores, principalmente ao buscar-se estratégias que privilegiem os subsunçores dos estudantes, bem como a promoção de seu papel ativo em todo o processo de aprendizagem. Visando atingir essas características, desenvolveu-se um organizador prévio, uma unidade didática fundamentada segundo a teoria de aprendizagem significativa, desenvolvendo, assim, um ambiente rico em aprendizagem sobre Geometria Plana.

Verificando a falta de alguns subsunçores dos estudantes sobre Geometria Plana, como por exemplo formas de calcular a área de figuras planas, planejou-se um organizador prévio para sanar essas lacunas, para posteriormente compreender sobre Geometria Espacial. Os dados coletados apresentam indícios que a unidade didática utilizada proporcionou a construção de novos conhecimentos, de Geometria Plana para a maioria dos estudantes, principalmente voltado para as fórmulas do cálculo de área.

Entre os resultados obtidos, percebe-se que a maioria dos estudantes gostou das atividades, da participação ativa no processo da construção do seu conhecimento, porém, alguns mostraram a insatisfação na realização das atividades, pois prefeririam "receber" o conhecimento pronto para aprender de forma mecânica.

Outro aspecto negativo é referente aos estudantes que não participaram das atividades e relataram que não compreenderam o conteúdo matemático; a não participação apresenta indícios que faltou predisposição para realização das atividades, principalmente pelo desinteresse sobre a disciplina de Matemática. O estudante não tendo interesse no assunto, não terá predisposição em aprender, desta forma, Ausubel (2003) afirma que dificilmente ocorrerá uma aprendizagem significativa, pois a predisposição é uma característica elementar. Desta forma, as atividades só apresentam resultados positivos para os estudantes que se mostraram dispostos em realizar as atividades e aprender.

Portanto, os resultados evidenciam que nem sempre as atividades planejadas atingiram a totalidade da turma, em que muitas vezes os educadores buscam estratégias interativas e dinâmicas para construção do conhecimento em sala de aula, mas não se consegue atingir o estudante, pois ele prefere receber as informações ou não está disposto a participar da aula. Porém, nessa pesquisa evidenciou que esse perfil de estudante desinteressado é a minoria presente nas salas de aulas, que os estudantes estão percebendo que para 
compreender e realmente aprender é necessário ser ativo cognitivamente para se atribuir significado ao conteúdo estudado. Entretanto tem-se a conviçcão que se a unidade didática fosse aplicada em outra turma, certamente os resultados seriam diferentes, mas espera-se que ela tenha a mesma ou uma eficácia melhor do que a encontrada nesta pesquisa. Diante destes fatos, espera-se que esta unidade didática sirva de modelo ou de meio para motivar outros docentes a inovarem nas suas aulas, criando estratégias que privilegiam o conhecimento prévio do estudante e tornando-o um sujeito ativo na sua aprendizagem.

\section{REFERÊNCIAS}

ARBACH, Nelson. $\mathbf{O}$ ensino de geometria plana: o saber do aluno e o saber escolar. 2002. 96 f. Dissertação (Mestrado) - Pontifícia Universidade Católica de São Paulo, Programa de Pós-Graduação em Educação Matemática, 2002.

AUSUBEL, David Paul. Aquisição e retenção de conhecimento: uma perspectiva cognitiva. Lisboa: Paralelo, 2003.

AUSUBEL, David Paul; NOVAK, Joseph Donald; HANESIAN, Helen. Psicologia Educacional. 2. ed. Rio de Janeiro: Interamericana, 1980.

BRASIL. Ministério da Educação e do Desporto. Ciências da natureza, matemática e suas tecnologias. Brasília: Ministério da Educação, Secretaria de Educação Básica, 2006.

BRASIL. Ministério da Educação. Base Nacional Comum Curricular: Educar é a base. Brasília: MEC, 2017. Disponível em: <http://basenacionalcomum.mec.gov.br/ images/BNCC_20dez_site.pdf $>$. Acesso em: 07 jan. 2018.

BRASIL. Ministério da Educação. Secretaria de Educação Fundamental. Parâmetros Curriculares Nacionais: Matemática. Brasília: MEC, 1998.

BRASIL. Ministério da Educação. Secretaria de Educação Média e Tecnológica. PCN + ensino médio: orientações educacionais complementares aos Parâmetros Curriculares Nacionais : ciências da natureza, matemática e suas tecnologias. Brasília: Ministério da Educação, 2002.

MIRAS, Mariana. Um ponto de partida para a aprendizagem de novos conteúdos: os conhecimentos prévios. In: COLL, César et al. O construtivismo na sala de aula. 6. ed. São Paulo: Ática, 1999. Cap. 3. p. 57-78.

MOREIRA, Marco Antonio. O que é afinal aprendizagem significativa. In: MOREIRA, Marco Antonio. Aprendizagem significativa: a teoria e textos complementares. São Paulo: Livraria de Física, 2011a.

MOREIRA, Marco Antonio. Teorias de aprendizagem. 2. ed. ampl. São Paulo: EPU, 2011b.

MOREIRA, Marco Antonio; MASINI, Elcie Aparecida Fortes Salzano. Aprendizagem significativa: a teoria de David Ausubel. 2. ed. São Paulo: Centauro, 2006. 